\title{
Ecological interactions between hatchery and wild fish: a case study based on the highly piscivorous Japanese Spanish mackerel
}

\author{
Kaori Nakajima ${ }^{1}$, Shuichi Kitada ${ }^{1, *}$, Hideki Yamazaki ${ }^{2}$, Hiromasa Takemori ${ }^{3}$, \\ Yasuhiro Obata ${ }^{4}$, Akio Iwamoto ${ }^{5}$, Katsuyuki Hamasaki ${ }^{1}$ \\ ${ }^{1}$ Dept. Marine Biosciences, Tokyo University of Marine Science and Technology, Tokyo 108-8477, Japan \\ ${ }^{2}$ Momoshima Laboratory, National Research Institute of Fisheries and Environment of Inland Sea, \\ Fisheries Research Agency (FRA), Hiroshima 722-0061, Japan \\ ${ }^{3}$ Kagawa Prefectural Fisheries Experimental Station, Takamatsu 761-0111, Japan \\ ${ }^{4}$ National Research Institute of Fisheries and Environment of Inland Sea, FRA, Hiroshima 739-0452, Japan \\ ${ }^{5}$ National Research Institute of Aquaculture, FRA, Mie 516-0193, Japan
}

\begin{abstract}
If the release of hatchery-reared juveniles exceeds the carrying capacity of the environment, the growth rate of wild fish may decrease or hatchery fish might displace wild fish because of competition for prey and space, or cannibalism. However, limited evidence is available to confirm these ecological effects. Therefore, we used census-marking experiments to investigate the ecological interactions between hatchery and wild fish in the large piscivorous species Japanese Spanish mackerel (JSM) Scomberomorus niphonius in the Seto Inland Sea. We analysed the relationship between the mean body weight and population size of Age $0 \mathrm{JSM}$, and the relationship between the biomass of juvenile Japanese anchovy Engraulis japonicus, which is the principal prey fish of JSM, and that of Age 0 JSM. We also estimated the spawner-recruit relationship. We measured the body sizes of 5008 JSM juveniles during July and December between 1999 and 2005 in the eastern Seto Inland Sea, and 551 hatchery fish were identified in the sample based on examinations of marked otoliths. There was a negative correlation between the mean body weight and population size of Age 0 fish, which clearly demonstrated the density-dependent growth of Age 0 JSM. The $\sim 35 \%$ variation in the biomass of Age 0 JSM was explained by the biomass of prey fish. Hatchery fish tended to be larger than wild fish, and they had better growth performance. Our analysis showed that hatchery fish reduced the growth rate of wild fish and displaced the wild fish in terms of biomass when hatchery fish stocking exceeded the carrying capacity of the environment.
\end{abstract}

KEY WORDS: Displacement of wild fish · Carrying capacity $\cdot$ Density-dependent growth $\cdot$ Prey fish dynamics · Otolith marking $\cdot$ Scomberomorus niphonius $\cdot$ Marine stock enhancement

\section{INTRODUCTION}

The potential to increase fish populations by means of releasing juveniles may generally depend on intra- and interspecific density-dependent interactions in the community (Peterman 1991). Surplus carrying capacity is therefore essential for successful

${ }^{*}$ Corresponding author. Email: kitada@kaiyodai.ac.jp fishery stock enhancement by releasing juveniles. The carrying capacity for a given fish population can be affected by prey abundance, space and predator-prey relationships (Salvanes et al. 1992), and it can be defined as the biomass level that can be supported by the available food resources in the absence of harvesting (Frèchette 1991, Svåsand et al. 2000). If

(C) The authors 2013. Open Access under Creative Commons by Attribution Licence. Use, distribution and reproduction are unrestricted. Authors and original publication must be credited. 
the release of juveniles exceeds the carrying capacity, the growth rate of wild fish may decrease or hatchery fish may displace wild fish because of competition for prey and space, or cannibalism (e.g. Walters 1988, Hilborn 1992). In such cases, the release of hatchery-reared fish (hereafter hatchery fish) may reduce wild fish production. This issue is therefore one of the most important topics related to fish stock enhancement and sea ranching.

The displacement of wild fish by hatchery fish has been discussed for pink salmon Oncorhynchus gorbuscha (Hilborn \& Eggers 2000, Wertheimer et al. 2004) and coho salmon O. kisutch (Sweeting et al. 2003). Wide-ranging ecological studies of the Atlantic cod Gadus morhua have shown that gobies are the principal prey of juvenile cod and that annual variations in the cod-carrying capacity are largely dependent on this prey group (Salvanes et al. 1992, Svåsand et al. 2000). An ecosystem simulation model suggested that recruitment beyond the maximum estimated potential production of $0.5 \times 10^{6}$ to $1.3 \times 10^{6} \mathrm{ind}$. $\mathrm{yr}^{-1}$ would reduce overall cod production in a fjord because of food shortages and cannibalism (Salvanes et al. 1992). An empirical analysis of red sea bream Pagrus major in Kagoshima Bay detected a negative correlation between the catches of hatchery and wild fish, and it was suggested that competition between hatchery and wild fish had caused the displacement of wild fish because of the limited carrying capacity of this semi-enclosed bay (Kitada \& Kishino 2006). However, little evidence is available to confirm the ecological impacts of hatchery fish on wild fish.

To address this issue, we used census-marking experiments to investigate the ecological interactions between hatchery and wild Japanese Spanish mackerel (JSM) Scomberomorus niphonius, which is a large piscivorous fish that is distributed mainly off the western coast of Japan. We tested the hypothesis that hatchery fish displace wild fish by examining the density-dependent growth of the 2 types of fish. We analysed the effect of hatchery releases on wild populations in terms of the growth reduction of wild JSM in the Seto Inland Sea (SIS). After briefly reviewing the JSM catch history, stock enhancement programme and fishery biology in the SIS, we estimated the relationship between the body weight (BW) and population size of Age 0 JSM in the SIS and estimated the change in food supply (prey fish abundance) as an index of the JSM-carrying capacity. We then analysed both the relationship between the biomass of prey fish and Age 0 JSM and the spawner-recruit relationship. Finally, we estimated the effects of the food supply on the growth of hatch- ery and wild JSM by comparing their growth measurements for 6 mo after release in the eastern SIS (ESIS) during the period from 1999 to 2005. Our analysis highlighted the interaction between hatchery and wild JSM, as we detected a growth reduction in wild fish when stocking exceeded the food supply.

\section{JSM fishery and stock enhancement}

JSM is an important fisheries resource, especially in the SIS (Fig. 1). The JSM fishery mainly involves set nets, drift nets and gill nets, and it targets mature fish in their spawning grounds during spring and immature young fish during autumn. The annual JSM catch from the SIS ranged between 900 and $1700 \mathrm{t}$ from 1953 to 1975 , but it increased during the 1980s and peaked at 6255 t in 1986 (Fig. 2; Ministry of Agriculture, Forestry and Fisheries 1955-2012). The increase in the catch was attributed mainly to improved fishing efficiency when drift nets with a small mesh size were used and to the introduction of an autumn fishing season that targeted young fish (Nagai 2003). However, the annual catch has decreased drastically since 1987, and reached a historical low of $196 \mathrm{t}$ in 1998, probably because of overfishing with small-mesh nets.

The Japan Sea Farming Association, which merged with the Fisheries Research Agency in 2003, sought to increase the depleted commercial JSM catch by initiating a stocking programme in 1998, and fishermen voluntarily refrained from targeting young fish with drift nets in the ESIS during autumn. In 2002, the Fisheries Agency of Japan implemented a stock recovery plan that involved the regulation of fishing for immature young fish during autumn and stocking the entire SIS with hatchery-reared juveniles (Kobayashi 2003). Two groups of hatchery fish were released with different chemical marks on their otoliths, i.e. juveniles measuring about $40 \mathrm{~mm}$ in total length (TL) and juveniles with a TL of about $100 \mathrm{~mm}$. A total of 1527000 juvenile JSM were released in the ESIS between 1998 and 2010; the $100 \mathrm{~mm}$ release group accounted for $78.4 \%$ of the total released. The $40 \mathrm{~mm}$ release group has not been stocked since 2004 (Obata et al. 2007, 2008, Yamazaki et al. 2007; Fisheries Agency of Japan and Fisheries Research Agency [http://abchan.job.affrc.go.jp/index1.html]). In total, $608000 \mathrm{JSM}$ juveniles have been released in the western SIS (WSIS) since 2002, with $40 \mathrm{~mm}$ TL juveniles comprising $40.7 \%$ of the released fish. In the ESIS, the mean contribution (mean \pm SD) of the hatchery fish to the total catch between 2006 and 


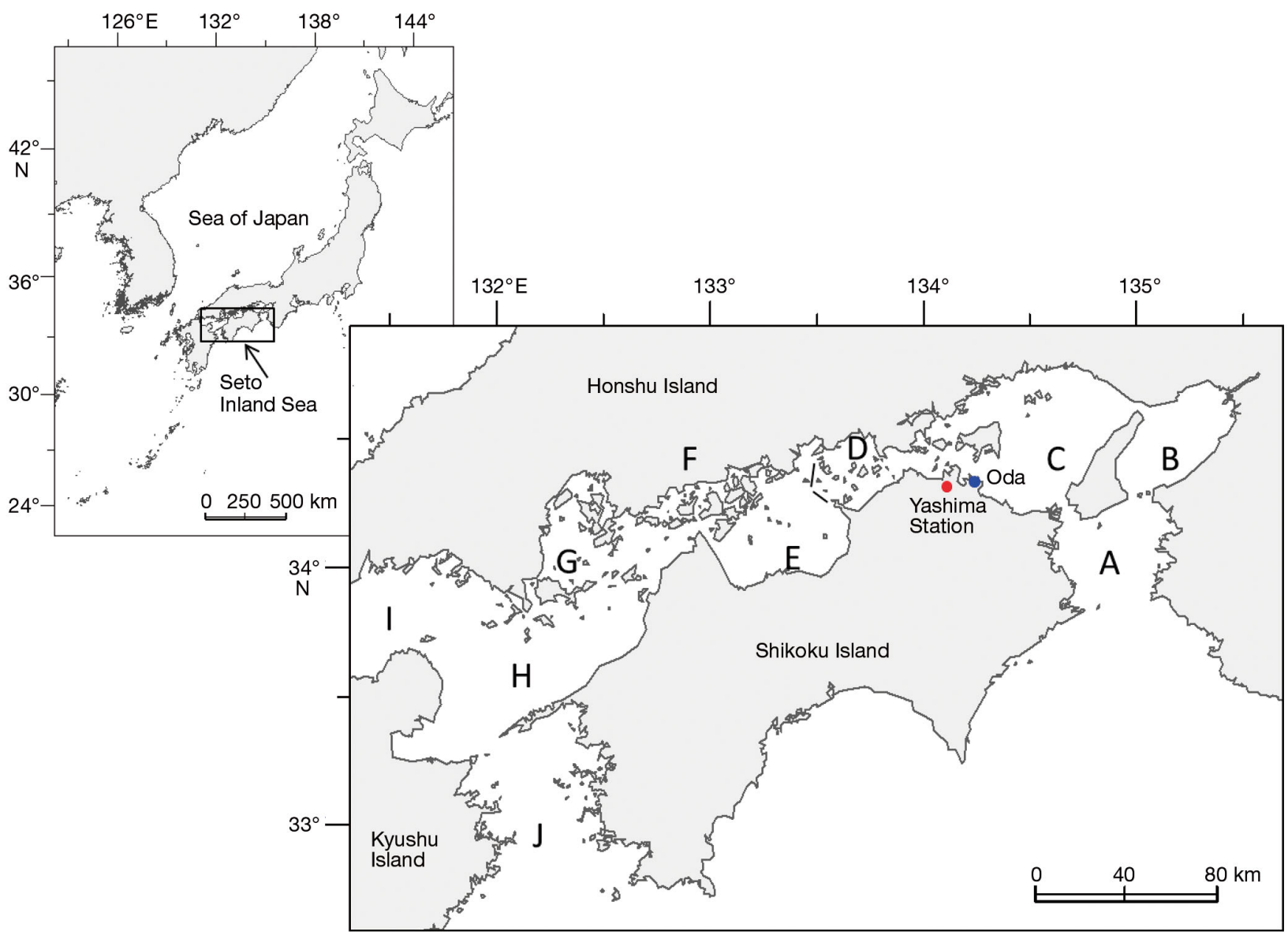

Fig. 1. Map of the Seto Inland Sea, southwestern Japan (inset), showing the eastern (A to D) and western (E to I) parts. A: Kii Channel; B: Osaka Bay; C: Harimanada; D: Bisanseto; E: Hiuchinada; F: Bingo-Geiyoseto; G: Akinada; H: Iyonada; I: Suounada; J: Bungo Channel

2009, expressed as a percentage of the total number of released fish in the samples examined (n), was estimated to be $23.7 \pm 17.2 \%(\mathrm{n}=4360), 19.0 \pm 13.0 \%$ $(\mathrm{n}=2359), 12.8 \pm 9.2 \%(\mathrm{n}=890), 8.9 \pm 5.7 \%(\mathrm{n}=485)$ and $6.0 \pm 3.6 \%(\mathrm{n}=402)$ for fish aged 0 to $4 \mathrm{yr}$, respectively. However, the mean contribution of hatchery fish was lower in the WSIS than in the ESIS, i.e. $2.6 \pm 2.4 \%(\mathrm{n}=5420), 0.9 \pm 0.4 \%(\mathrm{n}=6351), 2.4 \pm$ $1.5 \%(\mathrm{n}=1335), 2.6 \pm 0.7 \%(\mathrm{n}=445)$ and $0.7 \pm 1.3 \%$ $(\mathrm{n}=142)$ for fish aged 0 to $4 \mathrm{yr}$, respectively (National Association for the Promotion of Productive Sea 2007-2010). The JSM catches from the ESIS and WSIS were the same after 1998 (Fig. 2), which suggests that the food supply available for JSM might have differed little between the 2 areas in recent years. The lower impact of stocking on the WSIS might be because fewer fish were released and they were smaller at the time of release (i.e. lower likelihood of lower likelihood of survival). Indeed, the recapture rates were $6.5 \pm 0.9 \%$ for the $40 \mathrm{~mm}$ release group and $16.3 \pm 0.8 \%$ for the $100 \mathrm{~mm}$

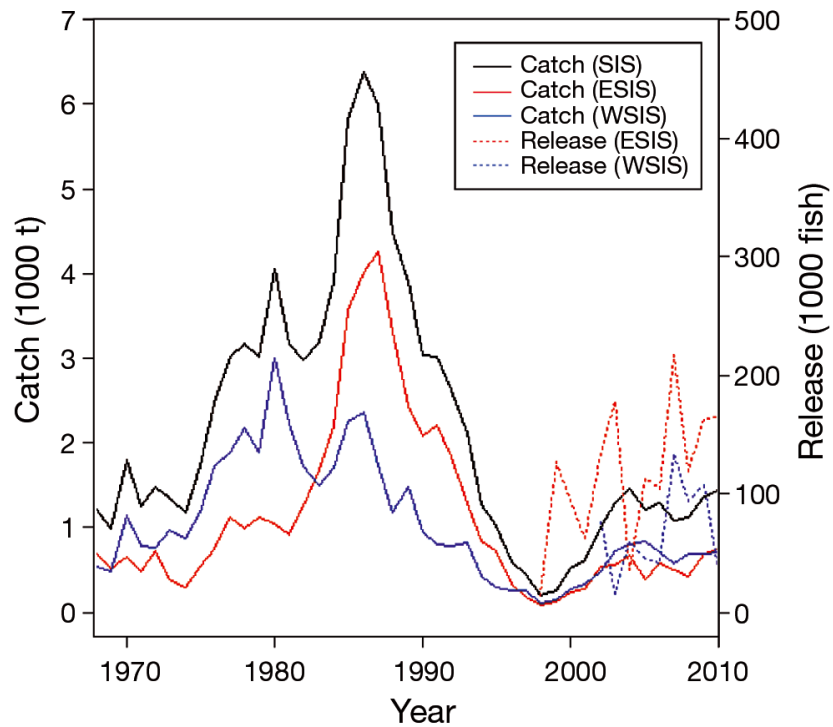

Fig. 2. Scomberomorus niphonius. Changes in the annual catch of Japanese Spanish mackerel from the Seto Inland Sea (SIS) (1968 to 2010), and the annual number of fish released into the eastern SIS (ESIS) since 1999 and western SIS (WSIS) since 2002 
release group in the ESIS (Obata et al. 2008), whereas they were very low (0 to $1.8 \%$ ) between 2006 and 2009 in the WSIS, reflecting the smaller size at release (National Association for the Promotion of Productive Sea 2007-2010). The JSM release programme in the ESIS appeared, thus, to have had a greater impact on the wild population than the releases in the WSIS. Therefore, we compared growth performance of young hatchery and wild JSM in the ESIS as described in 'Materials and methods: Growth of wild and hatchery JSM' below.

\section{Fishery biology of JSM}

According to studies on fishery biology (Kishida et al. 1985, Kishida 1986, 1989, Kishida \& Aida 1989, Nagai et al. 1996, Kono et al. 1997, Takemori et al. $2005 a, b)$ and early life ecology (Shoji \& Tanaka 2001, 2005, Shoji et al. 1997, 1999a, 2002, 2003), the life history of JSM can be summarized as follows. This species has an estimated life span of $>6 \mathrm{yr}$ and reaches maturity at 2 to $3 \mathrm{yr}$. In the SIS, JSM spawns mainly in May and June in the waters of Bisanseto, Harimanada and Osaka Bay in the ESIS, and Akinada, Bingo-Geiyoseto and Hiuchinada in the WSIS (Fig. 1). Newly hatched larvae have a standard length (SL) of $\sim 4 \mathrm{~mm}$ and they grow to an SL of $\sim 6 \mathrm{~mm}$ within $5 \mathrm{~d}$ of hatching. They depend on their endogenous nutrition source before they begin to feed on prey organisms. They have a strong piscivorous habit from their first feeding, and the larvae and juveniles feed mainly on the larvae of clupeid fish such as Japanese anchovy Engraulis japonicus. JSM larvae reach the juvenile stage at an SL of $\sim 12 \mathrm{~mm}$ within $10 \mathrm{~d}$ of hatching; the duration of their larval stage may be the shortest of all fish species. JSM larvae have a rapid growth rate, although their early mortality rate is considered to be very high. Shoji \& Tanaka (2005) reported that JSM juveniles with an SL of $30 \mathrm{~mm}$ were voracious feeders, with a high daily food intake (66.1 to $82.6 \%$ body mass [dry weight]). Based on the daily intake determined in a laboratory study, the afore-mentioned authors estimated that the release of 100000 JSM juveniles with an SL of $30 \mathrm{~mm}$ might lead to the consumption of 510000 to 640000 Japanese anchovy larvae during the first day of release.

The young JSM grow rapidly and recruit to the fishery stock during August/September when they have a fork length (FL) of $\sim 40 \mathrm{~cm}$ and a BW of 550 to $700 \mathrm{~g}$. The fish grow to $50 \mathrm{~cm}$ FL and 1 to $1.5 \mathrm{~kg} \mathrm{BW}$, before migrating to the Kii Channel and/or Bungo
Channel in the southern part of the ESIS and WSIS, respectively, during late autumn and winter. After overwintering, they migrate to the inner part of the SIS to feed and spawn. This annual migration pattern is repeated throughout their life cycle in the SIS. Mark-recapture experiments have shown that juveniles migrate between the ESIS and WSIS, although the migration of adult fish between these areas has not been investigated. Of 592508 juveniles released in the ESIS from 2006 to 2009, 50392 were recaptured. Among them, 45637 (90.6\%) and 4755 (9.4\%) fish were recaptured in the ESIS and WSIS, respectively. Of 252803 juveniles released in the WSIS from 2006 to 2009, $437(39.3 \%)$ and $675(60.7 \%)$ were recaptured in the ESIS and WSIS, respectively (National Association for the Promotion of Productive Sea 2007-2010). There were no genetic differences between the JSM samples taken from the ESIS and WSIS (K. Nakajima et al. unpubl. data), which suggests high gene flow between the 2 areas, thereby supporting the results of the mark-recapture experiments.

\section{MATERIALS AND METHODS}

\section{Population dynamics of JSM and food supply}

In general, fishing effort data are necessary to estimate sizes of fish populations. Published statistics are, however, not available for fishing efforts on JSM, so we analysed public data on the biomass and population sizes of JSM in different age groups, which were estimated using a virtual population analysis (Pope 1972) based on catch history (Fisheries Agency of Japan and Fishery Research Agency [http://abchan.job.affrc.go.jp/index1.html]). The same information source also mentioned a change in the average BW of newly recruited JSM (Age 0 fish). To infer density-dependent growth, we first examined the relationship between mean $\mathrm{BW}(w, \mathrm{~kg})$ and population size $(N$, individuals) of Age 0 fish in the SIS between 1987 and 2010, when the JSM catch decreased markedly, before recovering under the present JSM fisheries management strategy. The parameters used in the linear $N=\alpha-\beta w$ and curvilinear models $N=\alpha w^{-\beta}$ (Kleiber 1947, 1961, Bohlin et al. 1994) were estimated using linear and non-linear ordinary least-squares methods (OLS; Sokal \& Rohlf 1995), and the goodness of fit was compared using Akaike's information criterion (AIC; Akaike 1974).

We tested the relationship between the biomass of Age 0 JSM (response variable) and prey fish (ex- 
planatory variables), i.e. Japanese anchovy Engraulis japonicus larvae and Japanese anchovy, between 1987 and 2010. The estimated biomass of Japanese anchovy (including larvae) was reported for each month for fish aged 1 to 10 mo (Fisheries Agency of Japan and Fishery Research Agency [http://abchan. job.affrc.go.jp/index1.html]). Based on 1987 to 2010 data, we estimated the biomass of Japanese anchovy larvae eaten by JSM juveniles between May and July as the total biomass of Japanese anchovy larvae aged 1 to 2 mo. We then calculated the biomass of Japanese anchovy eaten by young JSM by subtracting the biomass of Japanese anchovy larvae (1 to 2 mo old) from the total Japanese anchovy biomass. Simple and multiple regression equations were estimated using the OLS method.

To describe the population dynamics and variation in recruitments, we fitted a Ricker recruitment function $R=\theta_{1} S \exp \left(-\theta_{2} S\right)$ (Ricker 1954, Hilborn \& Walters 1992) to the relationship between the estimated population sizes of spawners $S$ (Age 3 to $5+$ fish, including hatchery fish) and recruits $R$ (Age 0 wild fish) from 1987 to 2010 (Fisheries Agency of Japan and Fishery Research Agency [http://abchan. job.affrc.go.jp/index1.html]). We defined spawners as fish aged $>3$ yr based on Takemori (2006), who reported that the age at $100 \%$ maturity was $3 \mathrm{yr}$ in surveys from 1987 to 1990 and 2 yr in those conducted from 2000 to 2005 .

\section{Juvenile production and mark-recapture}

JSM juveniles were produced in two $150 \mathrm{kl}$ tanks at Yashima Station (Fig. 1) according to the methods described by Yamazaki \& Fujimoto (2003). The fertilized eggs used for seed production were artificially inseminated using mature fish captured in the ESIS by a fishing boat. The eggs were transferred to the Yashima Station and hatched at $17^{\circ} \mathrm{C}$ in the hatching tank. During seed production, the larvae were fed with larvae of red sea bream Pagrus major and Japanese flounder Paralichthys olivaceus and with defrosted flakes of Pacific sand eel Ammodytes personatus. JSM larvae were reared until they reached $\sim 40 \mathrm{~mm}$ TL, about 3 wk after hatching. After harvesting the intensive seed production tanks, some juveniles were transferred to nursery facilities near the release sites and reared until they reached $\sim 100 \mathrm{~mm} \mathrm{TL}$, after $2 \mathrm{wk}$. The juveniles were reared in net cages $(4 \times 4 \times$ $3 \mathrm{~m})$ and an earthen pond $(75 \times 75 \times 1.5 \mathrm{~m})$ on the coast at Oda, Kagawa Prefecture. Pacific sand eels were used to feed JSM juveniles in the nursery phase.
The otoliths of all JSM juveniles were marked using alizarin complexone (ALC; Dojindo Laboratories) (Kuwada \& Tsukamoto 1987, Tsukamoto 1988, Tsukamoto et al. 1989) after they hatched and reached $10 \mathrm{~mm}$ TL (see Obata et al. 2008 for details), before they were released into the waters of eastern Bisanseto and north-eastern Harimanada in the ESIS. The JSM juveniles in the $40 \mathrm{~mm}$ groups were released in early June, while the $100 \mathrm{~mm}$ groups were released from late June to early July. They were captured with set nets, gill nets and long lines in the waters of Harimanada until October and in the Kii Channel from November to January. Samples of Age 0 fish were collected from the major fish landing markets in the ESIS between July and December from 1999 to 2005. Sampling surveys collected every Age 0 JSM landed on selected days at the fish markets visited, and they were used to estimate the total hatchery and wild JSM landings (Kitada et al. 1992). Therefore, no fish were collected if no Age 0 JSM were landed on a selected sampling day. We bought the landed Age 0 JSM and measured the BW and FL of the hatchery and wild fish. We then dissected the fish and removed their otoliths (sagitta) at Yashima Station. The released fish were identified by the ALC marks on their otoliths under a fluorescence microscope.

\section{Growth of wild and hatchery JSM}

The morphometric relationships between FL and BW were analysed for hatchery and wild fish using the log-transformed allometric growth equation, $\operatorname{lnFL}$ $=\ln a+b \ln B W$. The parameters $(\ln a$ and $b)$ used in the equations were estimated with the OLS method. Analysis of covariance (ANCOVA) was performed to detect differences in the allometric growth coefficients $(b)$ and/or intercepts $(\ln a)$ of hatchery and wild fish based on the mean FL and BW. We evaluated differences in the mean BW of hatchery and wild fish for each month in each year using Welch's $t$-test.

We estimated the growth increments of hatchery and wild fish between July and December for each year from 1999 to 2005 and tested the differences as follows. If the growth increments for a year are $D_{\mathrm{H}}$ and $D_{\mathrm{W}}$ for hatchery and wild fish, respectively, the null hypothesis is $\mathrm{H}_{0}: D_{\mathrm{H}}=D_{\mathrm{W}}$ and the alternative hypothesis is $\mathrm{H}_{1}: D_{\mathrm{H}}>D_{\mathrm{W}} \cdot D_{\mathrm{H}}$ is estimated as $\hat{D}_{\mathrm{H}}=$ $\bar{x}_{2 \mathrm{H}}-\bar{x}_{1 \mathrm{H}}$, where $\bar{x}_{1 \mathrm{H}}$ is the average weight of the hatchery fish in July and $\bar{x}_{2 \mathrm{H}}$ is that in December. The variance is given by $V\left(\hat{D}_{\mathrm{H}}\right)=V\left(\bar{x}_{1 \mathrm{H}}\right)+V\left(\bar{x}_{2 \mathrm{H}}\right)-$ $2 \operatorname{Cov}\left(\bar{x}_{1 \mathrm{H}}, \bar{x}_{2 \mathrm{H}}\right)$, which is estimated by substituting 
$V\left(\bar{X}_{1 \mathrm{H}}\right)=\left(\mathrm{SD}_{1 \mathrm{H}}\right)^{2} / n_{1 \mathrm{H}}, V\left(\bar{x}_{2 \mathrm{H}}\right)=\left(\mathrm{SD}_{2 \mathrm{H}}\right)^{2} / n_{2 \mathrm{H}}$ and $\operatorname{Cov}\left(\bar{X}_{1 \mathrm{H}}, \bar{X}_{2 \mathrm{H}}\right)=r_{\left(\bar{X}_{1 \mathrm{H}}, \bar{X}_{2 \mathrm{H}}\right)} \sqrt{V\left(\bar{X}_{1 \mathrm{H}}\right) V\left(\bar{X}_{2 \mathrm{H}}\right)}$. SD is the standard deviation of the mean body size measurements in July or December from 1999 to 2005, $n$ is the sample size and $r$ is Pearson's correlation coefficient for $\bar{x}_{1 \mathrm{H}}$ and $\bar{x}_{2 \mathrm{H}}$. Here we estimated $r_{\left(\bar{x}_{1 \mathrm{H}}, \bar{x}_{2 \mathrm{H}}\right)}$ based on the data set of the mean body size measurements in July and December from 1999 to 2005. The growth increment for wild fish $D_{\mathrm{W}}$ is estimated in a similar way. The test statistic is $t=\left(\hat{D}_{\mathrm{H}}-\hat{D}_{\mathrm{W}}\right) / \sqrt{V\left(\hat{D}_{\mathrm{H}}-\hat{D}_{\mathrm{W}}\right)}$. The variance is estimated as $V\left(\hat{D}_{\mathrm{H}}-\hat{D}_{\mathrm{W}}\right)=V\left(\hat{D}_{\mathrm{H}}\right)+$ $V\left(\hat{D}_{\mathrm{W}}\right)-2 \operatorname{Cov}\left(\hat{D}_{\mathrm{H}}, \hat{D}_{\mathrm{W}}\right)$, where the covariance is estimated using the sample correlation coefficient between the estimates of $D_{\mathrm{H}}$ and $D_{\mathrm{W}}$ (from 1999 to 2005) as $\widehat{\operatorname{Cov}}\left(\hat{D}_{\mathrm{H}}, \hat{D}_{\mathrm{W}}\right)=r_{\left(\hat{D}_{\mathrm{H}}, \hat{D}_{\mathrm{W}}\right)} \sqrt{V\left(\hat{D}_{\mathrm{H}}\right) V\left(\hat{D}_{\mathrm{W}}\right)}$. For the null hypothesis, the test statistic follows a $t$ distribution with the following degrees of freedom: $\mathrm{df}=n_{1 \mathrm{H}}+$ $n_{2 \mathrm{H}}+n_{1 \mathrm{~W}}+n_{2 \mathrm{~W}}-4$. Finally, we tested the linear relationship between the biomass of Age 0 JSM and the growth increments of hatchery and wild fish. All analyses were performed using $\mathrm{R}$ language (R Development Core Team 2011).

\section{RESULTS}

After the maximum in 1988, the population size of JSM was negatively correlated with the mean weight of Age 0 fish (Fig. 3), which demonstrated that growth depended on the population size. The mean weight increased until 1995 as the population size decreased, whereas it decreased after 1996 until it reached its minimum in 2002. The linear and curvilinear models were fitted as $N=6042.19-4.503 \mathrm{~W}(\mathrm{AIC}=388.94)$ and $N=2.090 \times 10^{11} W^{-2.760}(\mathrm{AIC}=378.79)$, respectively. The AIC values clearly showed that the curvilinear model explained the relationship better (Fig. 3). The estimate of the exponent ( $\beta$ ) with the standard error was highly significant at $2.760 \pm 0.325$ $\left(t=-8.490, \mathrm{p}=2.17 \times 10^{8}\right)$.

The fluctuations in the biomass of Age 0 JSM appeared to be linked to the biomass of prey fish (Fig. 4). A similar goodness of fit was observed for the regression equations when Japanese anchovy larvae $\left(\mathrm{R}^{2}=0.348, \mathrm{p}=0.0024, \mathrm{AIC}=385.30\right)$ and Japanese anchovy larvae + Japanese anchovy $\left(\mathrm{R}^{2}=0.366, \mathrm{p}=\right.$ $0.0083, \mathrm{AIC}=386.65$ ) were used as explanatory variables. The regression coefficients for Japanese anchovy larvae were very similar for both regression models, at $0.0554 \pm 0.0162(t=3.443, \mathrm{p}=0.0024)$ and $0.0542 \pm 0.0164(t=3.308, \mathrm{p}=0.0034)$, although the regression coefficient for Japanese anchovy was not significant in the multiple regression model $(t=$

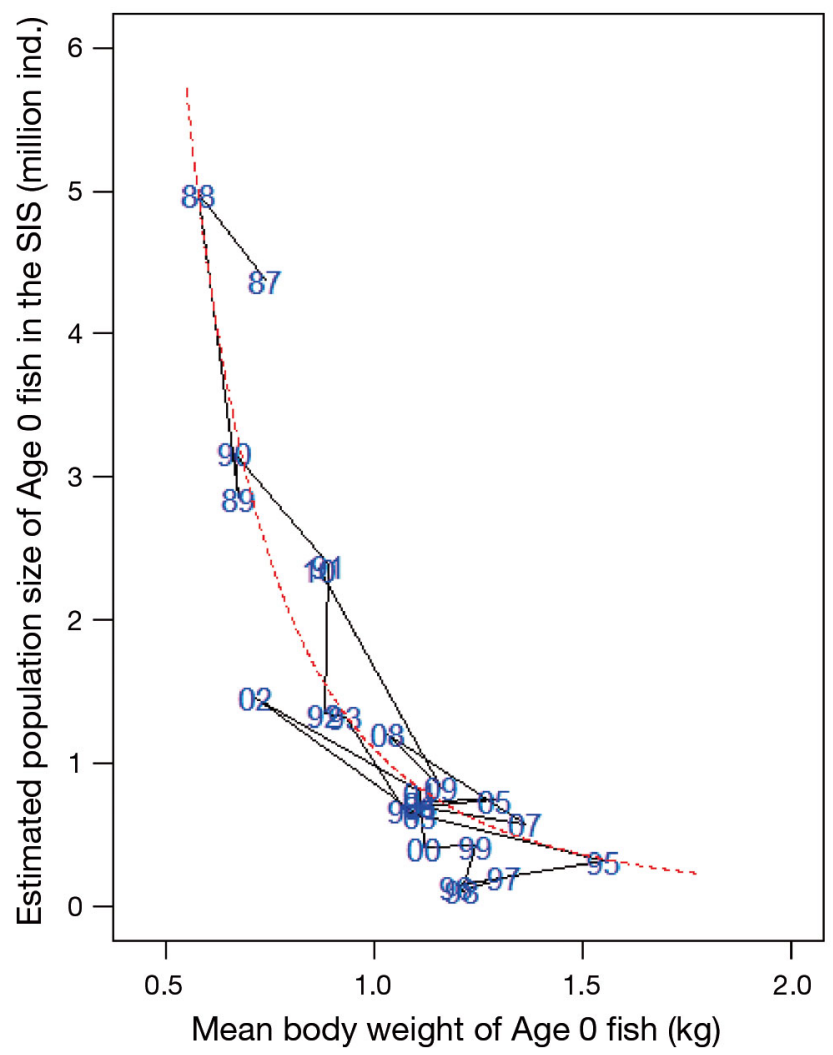

Fig. 3. Scomberomorus niphonius. Estimated population size versus mean body weight of newly recruited Japanese Spanish mackerel juveniles (Age 0 fish) in the Seto Inland Sea (SIS), with a fitted curvilinear model (dashed red line). The numbers on the graph indicate the years (1987 to 2010)

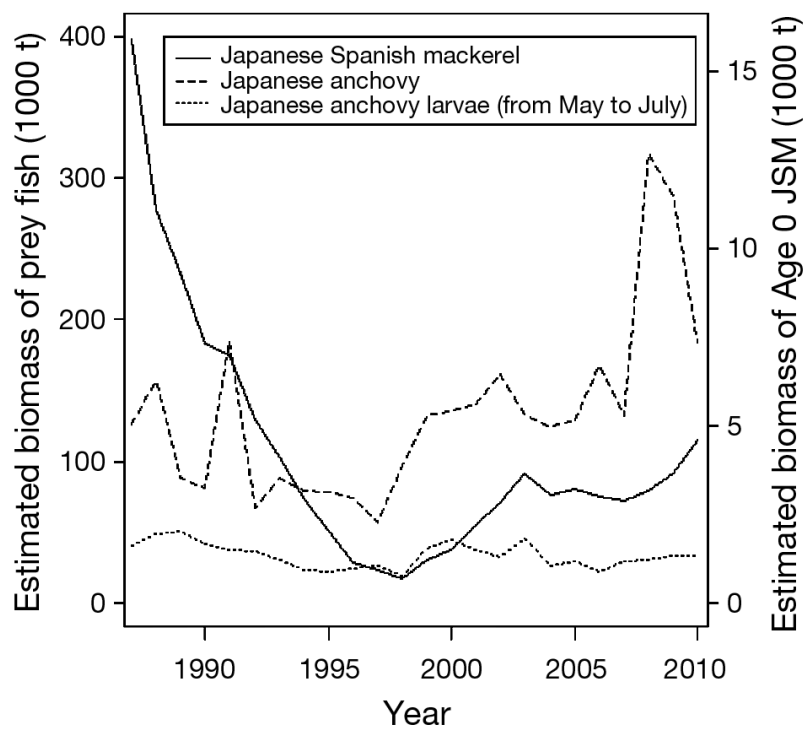

Fig. 4. Engraulis japonicus, Scomberomorus niphonius. Changes in the biomass of Japanese anchovy and Japanese anchovy larvae (during May and July) versus the biomass of Age 0 Japanese Spanish mackerel (JSM) in the Seto Inland Sea (1987 to 2010) 
0.762, $\mathrm{p}=0.4545)$. When Japanese anchovy alone was used as the explanatory variable, the model explained only $3.5 \%$ of the biomass fluctuations among Age 0 JSM $\left(\mathrm{R}^{2}=0.035, \mathrm{p}=0.3792\right.$, $\mathrm{AIC}=$ 394.71 ). The results showed that $\sim 35 \%$ of the variation in the Age 0 JSM biomass was explained by the biomass of Japanese anchovy larvae, reflecting the large difference between the biomass of JSM and that of anchovy larvae before 1996. The estimated Ricker recruitment function $\left(\hat{\theta}_{1}=6.2302 \pm 1.2586, \mathrm{p}=\right.$ $6.0 \times 10^{-5}$ and $\left.\hat{\theta}_{2}=0.0005 \pm 0.0002, \mathrm{p}=0.0093\right) \mathrm{de}-$ scribed the spawner-recruit relationship well (Fig. 5). The population sizes of spawners and recruits decreased continuously after 1987 and reached their minimum in 1998. Considering the increased fishing intensity as described in 'Introduction: JSM fishery and stock enhancement', overfishing appears to be the major cause of the decline in recruitment and the JSM catch. The population of spawners remained small even after 1998, although the number of recruits increased after 1999, with some variations.
During our study period (1999 to 2005), recruitment remained low in 1999 and 2000, whereas it was high in 2002 .

We measured the FL and BW of 5008 Age 0 fish, of which $551(11.0 \%)$ were identified as hatchery fish and $4457(89.0 \%)$ as wild fish (Table 1). The hatchery and wild fish grew rapidly and exhibited a similar growth pattern, although the mean BW of hatchery fish tended to be slightly higher than that of wild fish (Fig. 6). The relative growth curves were estimated as $\mathrm{BW}=2.259 \times 10^{-5} \mathrm{FL}^{2.846}\left(\mathrm{R}^{2}=0.991, \mathrm{p}=2.2 \times\right.$ $10^{-16}$ ) for hatchery fish and $\mathrm{BW}=1.768 \times 10^{-5} \mathrm{FL}^{2.883}$ $\left(\mathrm{R}^{2}=0.996, \mathrm{p}=2.2 \times 10^{-16}\right)$ for wild fish. The growth coefficients of hatchery fish $(\hat{b}=2.846 \pm 0.045, \mathrm{p}=$ $\left.2.0 \times 10^{-16}\right)$ and wild fish $(\hat{b}=2.883 \pm 0.027, \mathrm{p}=2.0 \times$ $10^{-16}$ ) indicated strong positively allometric growth, where BW increased faster than FL, although there was no significant difference between hatchery and wild fish in terms of their growth parameters (ANCOVA, $\mathrm{p}=0.5027$ ) and their mean weights after adjusting for FL $(p=0.2588)$. The average $( \pm S D)$ val-

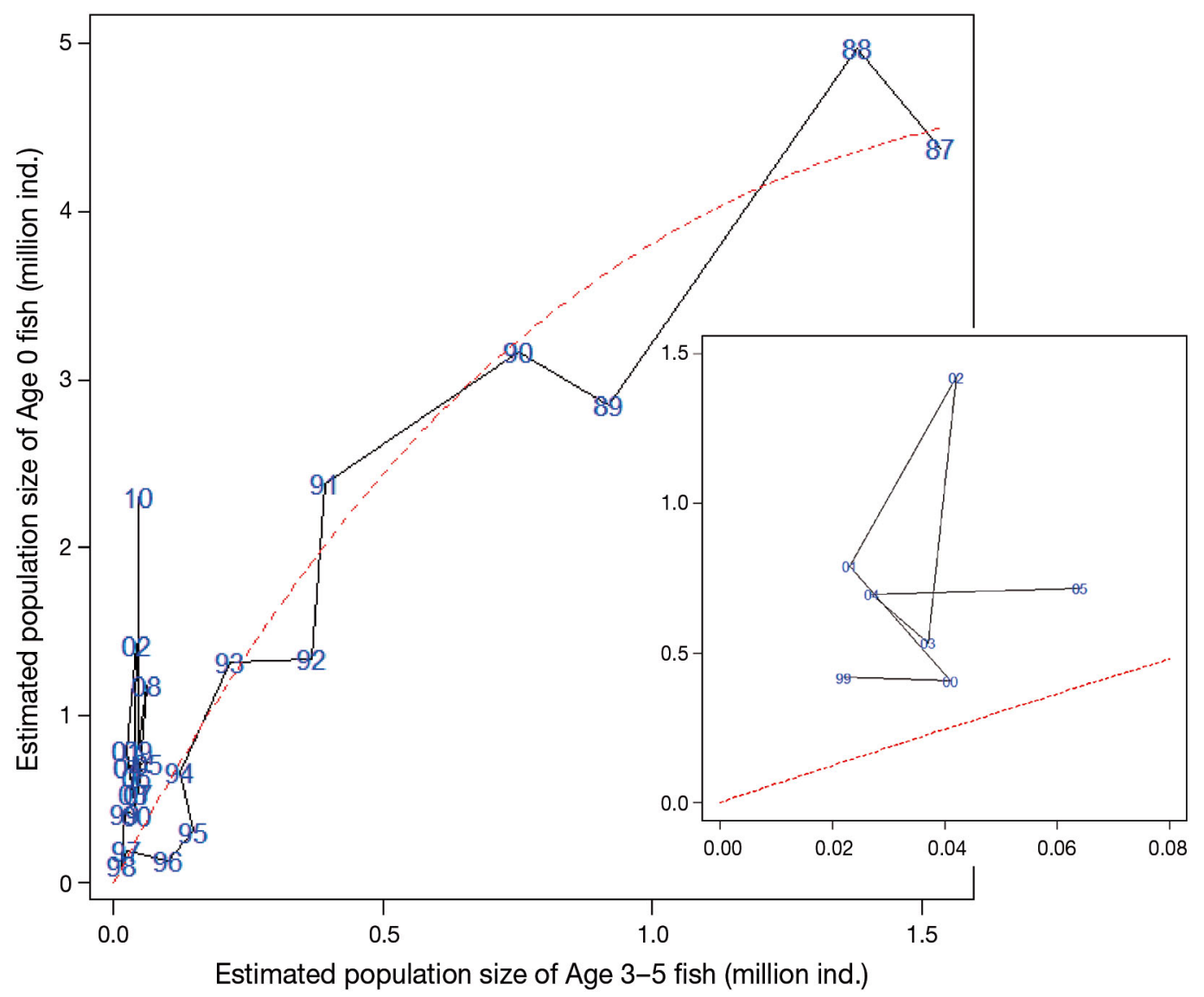

Fig. 5. Scomberomorus niphonius. Spawner-recruit relationship between Japanese Spanish mackerel in the Seto Inland Sea with a fitted Ricker recruitment function (dasehd red line), where the relationship is magnified (inset) for the years of our experiment (1999 to 2005) 
Table 1. Scomberomorus niphonius. Growth measurement data (means \pm SD) for hatchery and wild Japanese Spanish mackerel (Age 0 fish) in the eastern Seto Inland Sea

\begin{tabular}{|c|c|c|c|c|c|c|c|c|c|c|c|c|}
\hline \multirow[t]{2}{*}{ Year } & \multicolumn{6}{|c|}{-Wild fish } & \multicolumn{6}{|c|}{ - Hatchery fish } \\
\hline & Jul & Aug & Sep & Oct & Nov & Dec & Jul & Aug & Sep & Oct & Nov & Dec \\
\hline \multicolumn{13}{|c|}{ Fork length (mm) } \\
\hline 1999 & $224 \pm 21$ & $291 \pm 41$ & $410 \pm 36$ & $500 \pm 29$ & $520 \pm 54$ & $542 \pm 50$ & $236 \pm 27$ & $290 \pm 21$ & 367 & $470 \pm 3$ & - & 538 \\
\hline 2000 & $234 \pm 22$ & $295 \pm 29$ & $415 \pm 40$ & $508 \pm 33$ & $541 \pm 27$ & $556 \pm 21$ & $195 \pm 20$ & $312 \pm 17$ & $431 \pm 41$ & $530 \pm 24$ & - & $542 \pm 23$ \\
\hline 2001 & $210 \pm 28$ & $315 \pm 55$ & $421 \pm 33$ & $481 \pm 20$ & $509 \pm 22$ & $518 \pm 20$ & $216 \pm 17$ & $294 \pm 56$ & $409 \pm 32$ & 492 & $514 \pm 28$ & $535 \pm 4$ \\
\hline 2002 & $197 \pm 21$ & $247 \pm 40$ & $414 \pm 29$ & $473 \pm 25$ & $496 \pm 19$ & $494 \pm 24$ & $224 \pm 37$ & $294 \pm 35$ & $472 \pm 26$ & $494 \pm 40$ & $527 \pm 33$ & 515 \\
\hline 2003 & 169 & $301 \pm 38$ & $459 \pm 13$ & $479 \pm 23$ & $522 \pm 22$ & $541 \pm 18$ & $192 \pm 9$ & $333 \pm 37$ & $463 \pm 13$ & $497 \pm 27$ & $528 \pm 20$ & $541 \pm 19$ \\
\hline 2004 & 275 & $337 \pm 55$ & $459 \pm 70$ & $533 \pm 19$ & $565 \pm 23$ & $580 \pm 19$ & $217 \pm 11$ & $308 \pm 43$ & $485 \pm 7$ & 523 & 570 & 590 \\
\hline 2005 & $222 \pm 32$ & $326 \pm 52$ & $393 \pm 47$ & $492 \pm 25$ & $522 \pm 22$ & $524 \pm 25$ & $253 \pm 47$ & $351 \pm 44$ & - & $517 \pm 24$ & $544 \pm 5$ & $560 \pm 20$ \\
\hline \multicolumn{13}{|c|}{ Body weight (g) } \\
\hline 1999 & $104 \pm 29$ & $244 \pm 100$ & $629 \pm 199$ & $1147 \pm 201$ & $1199 \pm 326$ & $1394 \pm 352$ & $114 \pm 34$ & $227 \pm 21$ & 476 & $1012 \pm 45$ & - & 1341 \\
\hline 2000 & $127 \pm 36$ & $225 \pm 62$ & $685 \pm 206$ & $1111 \pm 175$ & $1308 \pm 187$ & $1442 \pm 136$ & $68 \pm 21$ & $267 \pm 43$ & $831 \pm 238$ & $1317 \pm 98$ & - & $1377 \pm 89$ \\
\hline 2001 & $87 \pm 31$ & $307 \pm 136$ & $632 \pm 131$ & $909 \pm 119$ & $1043 \pm 129$ & $1119 \pm 118$ & $90 \pm 17$ & $269 \pm 157$ & $623 \pm 98$ & 814 & $1077 \pm 119$ & $1341 \pm 48$ \\
\hline 2002 & $68 \pm 24$ & $142 \pm 72$ & $585 \pm 121$ & $853 \pm 151$ & $990 \pm 129$ & $951 \pm 145$ & $106 \pm 53$ & $230 \pm 67$ & $907 \pm 104$ & $1021 \pm 219$ & $1139 \pm 137$ & 1035 \\
\hline 2003 & 39 & $266 \pm 38$ & $879 \pm 65$ & $957 \pm 139$ & $1199 \pm 147$ & $1372 \pm 147$ & $61 \pm 9$ & $349 \pm 84$ & $959 \pm 50$ & $1111 \pm 163$ & $1323 \pm 138$ & $1457 \pm 130$ \\
\hline 2004 & 213 & $368 \pm 160$ & $878 \pm 293$ & $1366 \pm 144$ & $1530 \pm 168$ & $1659 \pm 139$ & $138 \pm 21$ & $287 \pm 92$ & $1026 \pm 25$ & 1215 & 1544 & 1656 \\
\hline 2005 & $108 \pm 48$ & $312 \pm 121$ & $510 \pm 191$ & $1015 \pm 152$ & $1178 \pm 149$ & $1163 \pm 165$ & $174 \pm 85$ & $415 \pm 129$ & - & $1253 \pm 150$ & $1396 \pm 102$ & $1479 \pm 148$ \\
\hline \multicolumn{13}{|c|}{ Sample size } \\
\hline 1999 & 38 & 51 & 4 & 70 & 15 & 14 & 3 & 2 & 1 & 2 & 0 & 1 \\
\hline 2000 & 6 & 173 & 125 & 58 & 35 & 34 & 24 & 39 & 20 & 5 & 0 & 8 \\
\hline 2001 & 40 & 231 & 219 & 177 & 209 & 67 & 5 & 5 & 4 & 1 & 6 & 2 \\
\hline 2002 & 185 & 394 & 260 & 532 & 176 & 76 & 11 & 23 & 10 & 21 & 9 & 1 \\
\hline 2003 & 1 & 49 & 5 & 103 & 118 & 103 & 52 & 46 & 25 & 42 & 61 & 29 \\
\hline 2004 & 1 & 15 & 6 & 15 & 18 & 14 & 4 & 7 & 2 & 1 & 1 & 1 \\
\hline 2005 & 22 & 71 & 73 & 470 & 110 & 74 & 3 & 14 & 0 & 46 & 7 & 7 \\
\hline
\end{tabular}

ues of BW (FL) in July (1999 to 2005) were $107.3 \pm$ $39.6 \mathrm{~g}(219.0 \pm 21.6 \mathrm{~mm})$ and $106.6 \pm 55.1 \mathrm{~g}(218.7 \pm$ $32.8 \mathrm{~mm})$ for hatchery and wild fish, respectively, while those in December (1999 to 2005) were $1383.7 \pm$ $188.8 \mathrm{~g}(545.9 \pm 23.5 \mathrm{~mm})$ and $1300.0 \pm 236.8 \mathrm{~g} \mathrm{(536.4 \pm}$ $27.8 \mathrm{~mm})$, respectively.

BW was strongly correlated with FL (Fig. 6), and BW reflected density-dependent growth, as shown in Fig. 3, so in the following we have focused on the BW analysis. Hatchery fish were significantly larger than wild fish in 2000, 2002, 2003 and 2005, whereas there were no differences in 1999, 2001, or 2004 (Fig. 7). The test statistics are summarized in Table 2. The BW variation was greater in the wild fish. The growth increments of hatchery and wild fish between July and December varied between years, with a mean \pm SD of $1276 \pm 181.8 \mathrm{~g}$ and $1193 \pm 203.7 \mathrm{~g}$, respectively (Table 3). The differences in growth increments ranged from -63 to $+250 \mathrm{~g}$, and the increment was higher in hatchery fish in 5 of the 7 years. We calculated p-values from the test statistics ( $t$-values) and degrees of freedom. We found that the growth increments (i.e. growth rate) of hatchery fish were higher than those of wild fish in the years 2001 and 2005 (p < 0.01; Table 3), and the growth increments became smaller with a greater biomass of Age 0 JSM (Fig. 8).

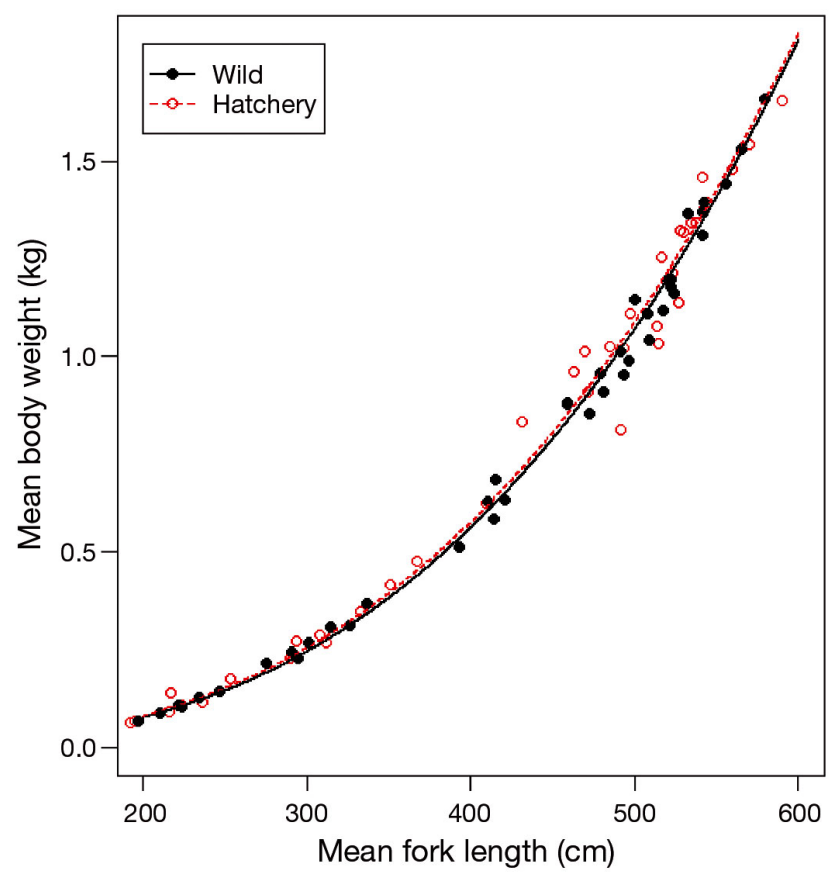

Fig. 6. Scomberomorus niphonius. Relationships between the mean fork length and mean body weight of hatchery $(\mathrm{n}=$ 551) (open circles with dashed line) and wild ( $\mathrm{n}=4457$ ) (solid circles with continuous line) Japanese Spanish mackerel (Age 0 fish) in the eastern Seto Inland Sea between July and December from 1999 to 2005 (data are shown in Table 1) 


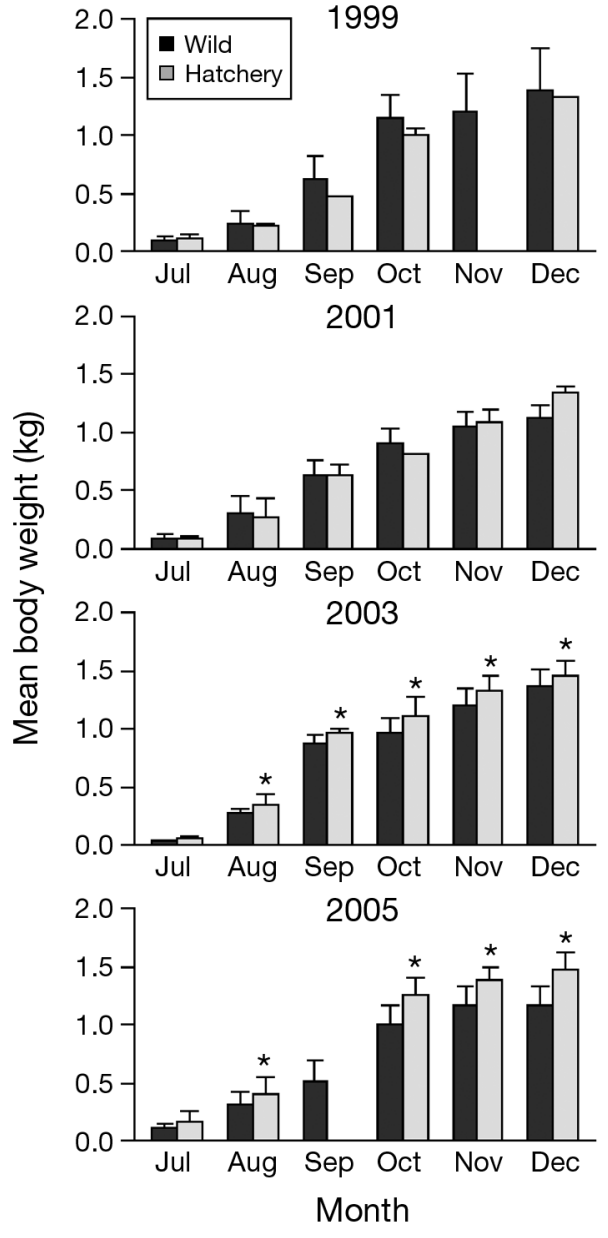

By contrast, there were no differences in the growth increments (i.e. growth rates) of hatchery and wild fish in 1999 and 2000 when the JSM biomass was small (in other words, the food supply per individual JSM was relatively abundant) (Table 3 ). The regression coefficients and intercepts were estimated to be $-1.3073 \pm 0.5605(t=-2.332, \mathrm{p}=0.1019)$ and $2423.16 \pm 494.87(t=4.896, \mathrm{p}=0.0163)$, respectively, for hatchery fish and to be $-1.4684 \pm 0.5083(t=$ $-2.889, \mathrm{p}=0.0631)$ and $2434.10 \pm 448.84(t=5.423$, $\mathrm{p}=0.0123$ ), respectively, for wild fish, based on data that excluded 1999 and 2000. The regression lines showed that the growth increment became smaller the higher the biomass of Age 0 fish $\left(R^{2}=0.6446\right.$ for hatchery and 0.7356 for wild fish) (Fig. 8).

\section{DISCUSSION}

We identified hatchery JSM Scomberomorus niphonius using the ALC marks on their otoliths, and we compared their growth with that of wild JSM.
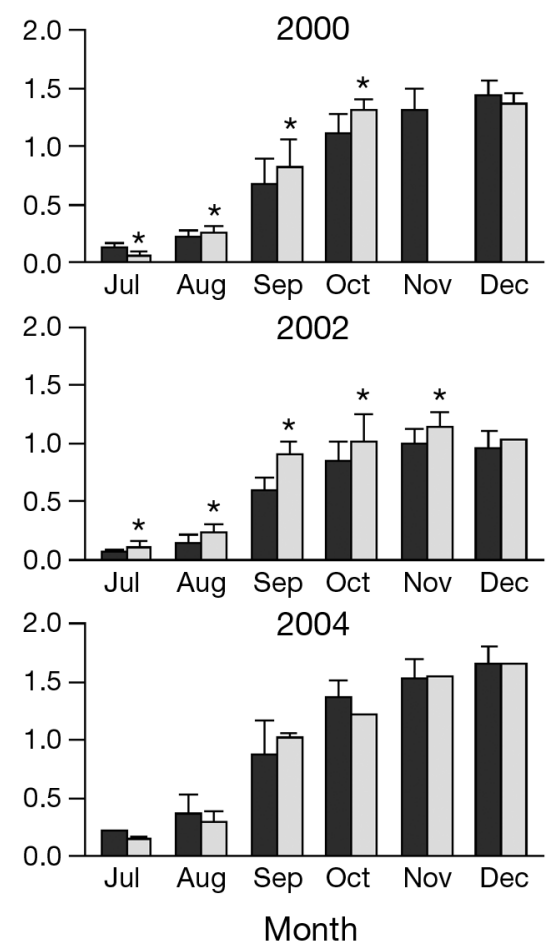

Fig. 7. Scomberomorus niphonius. Monthly changes in the mean body weight of hatchery $(n=551)$ and wild $(n=4457)$ Japanese Spanish mackerel (Age 0 fish) in the eastern Seto Inland Sea between July and December for each year from 1999 to 2005 (data are shown in Table 1). Asterisks indicate significant differences between hatchery and wild fish $(\mathrm{p}<0.05)$

ALC has a low marking cost and high mark retention (Svåsand et al. 2000) so it is often used to mark the otoliths of salmonids (Tsukamoto 1988) and marine fish, including red sea bream Pagrus major (Tsukamoto et al. 1989), Atlantic cod Gadus morhua (Blom et al. 1994), red drum Sciaenops ocellatus (Thomas et al. 1995) and turbot Scophthalmus maximus (Iglesias \& Rodriguez-Ojea 1997). In the present study, the mark retention time was not confirmed experimentally, although released JSM with ALCmarked otoliths were detected among Age 2 to 3 fish, and the ratios of released fish in the samples of Age 2 fish were similar to those in Age 0 to 1 fish in our subsequent fish market surveys (authors' unpubl. data). Therefore, the retention time should be sufficient for the unbiased detection of released fish within a year of release $(6 \mathrm{mo})$.

Wild fish had the same growth performance as hatchery fish when the food supply was relatively abundant (in 1999 and 2000), whereas hatchery fish competed with wild fish for food and performed better when the food supply was limited (2001 to 2005) 
Table 2. Scomberomorus niphonius. Test statistics for comparisons of the differences in the body weight of hatchery and wild Japanese Spanish mackerel. Bold type indicates significant differences $(p<0.05)$

\begin{tabular}{|cccccccc|}
\hline \multirow{2}{*}{ Year } & & Jul & Aug & Sep & Oct & Nov & Dec \\
\hline \multirow{2}{*}{1999} & $t$ & 0.4954 & 0.8329 & - & 3.386 & - & - \\
& $\mathrm{df}$ & 2.24 & 3.51 & - & 2.45 & - & - \\
& $\mathrm{p}$ & 0.6648 & 0.4577 & - & 0.0578 & - & - \\
2000 & $t$ & 3.8539 & 5.0333 & 2.5924 & 4.1628 & - & 1.6595 \\
& $\mathrm{df}$ & 5.88 & 78.17 & 23.78 & 6.47 & - & 15.80 \\
& $\mathrm{p}$ & $\mathbf{0 . 0 0 8 7}$ & $\mathbf{3 . 0 1 \times 1 0 ^ { - 6 }}$ & $\mathbf{0 . 0 1 6 0}$ & $\mathbf{0 . 0 0 5 0}$ & - & 0.1167 \\
2001 & $t$ & 0.3316 & 0.5369 & 0.1807 & - & 0.6883 & 6.0202 \\
& $\mathrm{df}$ & 7.88 & 4.13 & 3.20 & - & 5.34 & 1.39 \\
& $\mathrm{p}$ & 0.7488 & 0.6190 & 0.8674 & - & 0.5200 & 0.058 \\
2002 & $t$ & 2.3636 & 6.0968 & 9.5456 & 3.4829 & 3.1912 & - \\
& $\mathrm{df}$ & 10.25 & 25.06 & 9.96 & 20.76 & 8.74 & - \\
& $\mathrm{p}$ & $\mathbf{0 . 0 3 9 1}$ & $\mathbf{2 . 2 0 \times 1 0 ^ { - 6 }}$ & $\mathbf{2 . 5 0} \times \mathbf{1 0}$ & $\mathbf{0 . 0 0 2 2}$ & $\mathbf{0 . 0 1 1 4}$ & - \\
2003 & $t$ & - & 6.1379 & 2.6024 & 5.3773 & 5.5716 & 3.0193 \\
& $\mathrm{df}$ & - & 61.81 & 4.99 & 66.57 & 128.38 & 50.01 \\
& $\mathrm{p}$ & - & $\mathbf{6 . 5 6 \times 1 0 ^ { - 8 }}$ & $\mathbf{0 . 0 4 8 2}$ & $\mathbf{1 . 0 5} \times \mathbf{1 0}^{-\mathbf{6}}$ & $\mathbf{1 . 4 2} \times \mathbf{1 0}$ & $\mathbf{0 . 0 0 4}$ \\
2004 & $t$ & - & 1.5000 & 1.2240 & - & - & - \\
& $\mathrm{df}$ & - & 18.81 & 5.21 & - & - & - \\
& $\mathrm{p}$ & - & 0.1502 & 0.2734 & - & - & - \\
2005 & $t$ & 1.3166 & 2.7579 & - & 10.2582 & 5.3059 & 5.3436 \\
& $\mathrm{df}$ & 2.18 & 17.80 & - & 54.45 & 7.73 & 7.49 \\
& $\mathrm{P}$ & 0.3095 & $\mathbf{0 . 0 1 3 1}$ & & $\mathbf{2 . 5 0 \times 1 0 ^ { - 1 4 }}$ & $\mathbf{0 . 0 0 0 8}$ & $\mathbf{0 . 0 0 0 9}$ \\
& & & & & & &
\end{tabular}

Table 3. Scomberomorus niphonius. Increments in body weights of hatchery and wild Japanese Spanish mackerel between July and December, and test statistics for comparisons of the differences in the growth increments of hatchery and wild fish. Bold type indicates significant differences $(p<0.05)$

\begin{tabular}{|c|c|c|c|c|c|c|}
\hline \multirow[t]{2}{*}{ Year } & \multicolumn{2}{|c|}{$\begin{array}{l}\text { Growth increment } \\
\text { (body weight, g) }\end{array}$} & \multirow[t]{2}{*}{$\begin{array}{l}\text { Difference } \\
\qquad(a-b)\end{array}$} & \multirow[t]{2}{*}{$t$} & \multirow[t]{2}{*}{$\mathrm{df}$} & \multirow[t]{2}{*}{$\mathrm{p}$} \\
\hline & Hatchery (a) & Wild (b) & & & & \\
\hline 1999 & 1227 & 1290 & -63 & -0.835 & 52 & 0.7962 \\
\hline 2000 & 1309 & 1315 & -6 & -0.319 & 68 & 0.6246 \\
\hline 2001 & 1251 & 1032 & 219 & 9.189 & 110 & $1.44 \times 10^{-15}$ \\
\hline 2002 & 929 & 883 & 46 & 5.037 & 269 & $4.34 \times 10^{-7}$ \\
\hline 2003 & 1396 & 1333 & 63 & 4.420 & 181 & $8.49 \times 10^{-6}$ \\
\hline 2004 & 1518 & 1446 & 72 & 2.482 & 16 & 0.0123 \\
\hline 2005 & 1305 & 1055 & 250 & 4.812 & 102 & $2.59 \times 10^{-6}$ \\
\hline
\end{tabular}

capita food supply. The higher growth performance of hatchery fish in 2001 to 2005 suggests that releases exceeded the food supply and that hatchery and wild fish competed for food. Our analysis showed that hatchery fish reduced the growth rate of wild fish and displaced them in terms of biomass when stocking exceeded the food supply. The regression coefficients for growth increments versus the biomass of Age 0 fish (Fig. 8) showed that wild fish tended to exhibit a higher rate of growth increment reduction compared with hatchery fish, although this trend was not significant (wild: $t=-2.332, \mathrm{p}=$ 0.1019; hatchery: $t=-2.889, \mathrm{p}=$ 0.0631 ), which reflected the variation in the growth increments within a small sample size (5 yr). This suggested that the competition between hatchery and wild fish might be greater with a larger biomass, and that wild fish were slightly weaker than hatchery fish during densitydependent competition. We had insufficient data to determine the occurrence of cannibalism, so it was unclear whether hatchery fish actually displaced the wild fish via cannibalism. This is an area for further research.

The parent fish used for artificial fertilization were caught in the ESIS each year. We did not check for ALC marks on their otoliths, but the probability of using hatchery fish as parents should have been low given the mean contribution (= $14.1 \%$, calculated using the values given in 'Introduction: JSM fishery and stock enhancement') of

(Figs. 5 \& 8). The food supply per capita depended on variations in the recruitment of JSM and prey fish (Fig. 4). The small BW of Age 0 wild fish in 2002 (Table 3, Fig. 7) showed that the food supply available to JSM in the ESIS may have been particularly limited in 2002. The low per capita food supply may have been caused by the increased recruitment of JSM (Fig. 5), because the biomass of Japanese anchovy Engraulis japonicus larvae was not necessarily low in 2002 (Fig. 4). Indeed, the growth increment was the lowest for hatchery and wild FSM in 2002 (Table 3, Fig. 8), which reflected the low per hatchery fish to the total catch in the ESIS between 2006 and 2009. The juveniles were captive-reared for $3 \mathrm{wk}$ (40 mm TL) and $5 \mathrm{wk}$ (100 mm TL) after hatching and were exposed to natural selection after release. Thus, there might be no effect of domestication selection (e.g. Ford 2002) on the growth of hatchery fish. The released juveniles were reared from eggs that were artificially inseminated in early and late May, which was before the main JSM spawning season in the SIS (Sugino et al. 2005). According to Shoji \& Tanaka (2006) and Shoji et al. (1999b, 2002, 2005), JSM recruitment is determined several days 


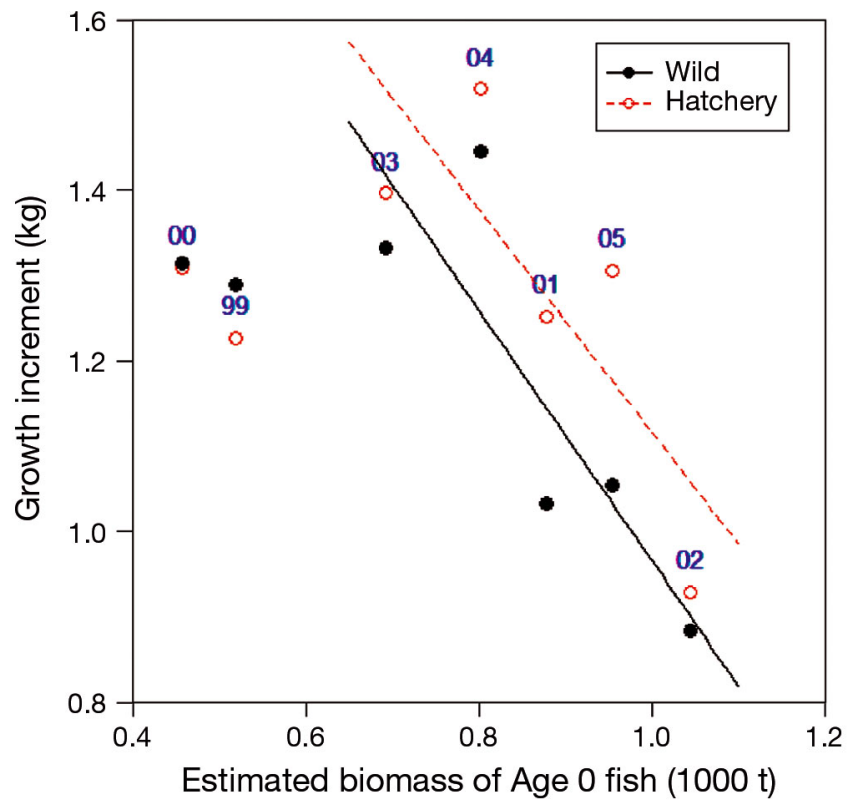

Fig. 8. Scomberomorus niphonius. Growth increments (mean body weight) versus estimated biomass of hatchery and wild Japanese Spanish mackerel (Age 0 fish) between July and December. The regression lines (dashed line) with open circles and (continuous line) with solid circles relate to hatchery and wild fish, respectively. The numbers on the graph indicate the years (1999 to 2005)

after hatching during the early juvenile stage and it is dependent on the abundance of prey fish larvae. In Hiuchinada in the SIS, the abundance of JSM larvae peaks in late May to early June. Therefore, the body size of hatchery fish should have been larger than that of wild fish when they were released into the natural habitat from early June (40 mm TL) to early July (100 mm TL). This appears to be the most likely cause of the higher growth performance of hatchery fish.

The negative correlation between the mean weight and population size of Age 0 fish (Fig. 3) showed clearly that the growth of Age 0 JSM in the SIS was dependent on the population size of Age 0 fish. The curvilinear model fit the relationship better, with an estimated exponent $(\beta)$ of 2.760 . The parameter $\beta$ describes a 'self-thinning process'. If a population is resource limited, the number of individuals per unit of area that can be supported is expected to be inversely related to the average body weight (Bohlin et al. 1994). This process is well known in plant populations but less well established in mobile animals (Bohlin et al. 1994). The exponent $\beta$ explains the relative food supply of an individual. A large $\beta$ value refers to a limited food supply, and the population size rapidly decreases against the increase in aver- age body weight. A $\beta$ value of $0.75(=3 / 4)$ has been suggested because the unit of the $3 / 4$ power of body weight $\left(\mathrm{kg}^{3 / 4}\right)$ is a suitable unit of metabolic body size ('Kleiber's rule'; Kleiber 1947, 1961). A review by Peters (1983) confirmed that this might be a useful approximation for homeotherms at least (Bohlin et al. 1994). Several estimates of $\beta$ have been made based on empirical studies of salmonid species, i.e. 1.33 for juvenile anadromous brown trout Salmo trutta (Armstrong 1997), 0.74 for juvenile steelhead trout Oncorhynchus mykiss (Keeley 2001, 2003), 0.939 for anadromous brown trout, 0.889 for resident brown trout and 1.067 for Atlantic salmon Salmo salar (Bohlin et al. 1994). In the present study, the $\beta$ value of 2.760 was much higher than the values for juvenile salmonid fish. In previous studies, however, the $\beta$ values were estimated from samples that contained the same cohorts, so they explained the self-thinning process of a cohort. By contrast, our $\beta$ value was estimated using different cohorts over a $24 \mathrm{yr}$ period (1987 to 2010). Therefore, this value does not describe the self-thinning process of a cohort, but it does explain the density-dependent growth of Age 0 JSM with a variable food supply each year. The value of 2.760 might be related to the highly piscivorous habits and rapid growth of JSM under a limited food supply.

An assumption of the JSM stock recovery plan in the ESIS was that stocking juveniles would effectively boost fishery production because of the high contribution rates of hatchery fish to the total catch and increased catch. However, our analysis showed that the abundance of JSM decreased due to overfishing of the spawners and that the catch recovery after 1999 may, rather, have been attributable to the increased abundance of prey fish. The large variation in the biomass of newly recruited JSM probably depended on variation in the abundance of prey fish, which feed on zooplankton. The food supply may also be affected by forces such as solar radiation, temperature, freshwater runoff and deep-water convection (Salvanes et al. 1992). Changes in these environmental conditions may have affected the abundance of prey fish, but the reason for the low prey fish abundance until the mid- or late 1990s (Fig. 4) is unknown. The JSM catches increased in the ESIS after the JSM stocking programme began (Fig. 2). Similarly, the JSM catch started to recover from 1999 on in the WSIS where no juveniles had been released and there was a significant positive correlation between the catches in the ESIS and WSIS $\left(\mathrm{R}^{2}=0.741\right.$, $\mathrm{p}=6.80 \times 10^{-8}$, figure not shown). After 2003, the JSM catches from the WSIS exceeded those from the 
ESIS, where there have been fewer releases since 2002 (Fig. 2). Thus, the trend in the JSM catch from the ESIS agrees well with that from the WSIS, suggesting that the dynamics of the JSM population after the initiation of the release programme were dependent largely on the dynamics of the prey fish populations, whereas they were not linked to the release of juveniles.

This top predator species will naturally affect the SIS ecosystem via its role in food webs. Our analysis of JSM could be generalized to other strongly piscivorous fish, such as the Pacific bluefin tuna Thunnus orientalis, which has been targeted for stock enhancement (Masuma et al. 2008), and hatchery releases of $T$. orientalis are planned for the near future by the Fishery Research Agency. The release of highly piscivorous fish such as JSM and T. orientalis should be considered very carefully to assess their potential impact on the ecosystem, including wild target populations.

Acknowledgements. We thank Ian Fleming and 3 anonymous reviewers for constructive comments on earlier versions of the manuscript. This study was funded by the Japan Society for the Promotion of Science (grant nos. 18380114 and 22380110).

\section{LITERATURE CITED}

Akaike H (1974) A new look at the statistical model identification. IEEE Trans Automat Contr 19:716-723

Armstrong JD (1997) Self-thinning in juvenile sea trout and other salmonid fishes revisited. J Anim Ecol 66:519-526

Blom G, Nordeide JT, Svåsand T, Borge A (1994) Application of two fluorescent chemicals, alizarin complexone and alizarin red S, to mark otoliths of Atlantic cod, Gadus morhua L. Aquacult Fish Manag 25(Suppl 1):229-243

Bohlin T, Dellefors C, Faremo U, Johlander A (1994) The energetic equivalence hypothesis and the relation between population density and body size in stream-living salmonids. Am Nat 143:478-493

Ford MJ (2002) Selection in captivity during supportive breeding may reduce fitness in the wild. Cons Biol 16: 815-825

Frèchette MM (1991) Carrying capacity and density dependence. ICES J Mar Sci 192:78

Hilborn R (1992) Hatcheries and the future of salmon in the Northwest. Fisheries (Bethesda) 17:5-8

$>$ Hilborn R, Eggers D (2000) A review of the hatchery programs for pink salmon in Prince William Sound and Kodiak Island, Alaska. Trans Am Fish Soc 129:333-350

Hilborn R, Walters CJ (1992) Quantitative fisheries stock assessment: choice, dynamics and uncertainty. Chapman \& Hall, New York, NY

Iglesias J, Rodriguez-Ojea G (1997) The use of alizarin complexone for immersion marking of the otoliths of embryos and larvae of the turbot, Scophthalmus maximus (L): dosage and treatment time. Fish Manag Ecol 4:405-417
Keeley ER (2001) Demographic responses to food and space competition by juvenile steelhead trout. Ecology 82: 1247-1259

> Keeley ER (2003) An experimental analysis of self-thinning in juvenile steelhead trout. Oikos 102:543-550

Kishida T (1986) Feeding habits of Japanese Spanish mackerel in the central and western waters of the Seto Inland Sea. Bull Nansei Reg Fish Res Inst 20:73-89 (in Japanese with English Abstract)

Kishida T (1989) Distribution and migration of Japanese Spanish mackerel based on the catch and effort data in the central and western waters of the Seto Inland Sea. Bull Nansei Reg Fish Res Inst 22:13-27 (in Japanese with English Abstract)

Kishida T, Aida K (1989) Maturation and spawning of Japanese Spanish mackerel in the central and western waters of the Seto Inland Sea. Bull Jpn Soc Sci Fish 55:2065-2074

Kishida T, Ueda K, Takao K (1985) Age and growth of Japanese Spanish mackerel in the central and western waters of the Seto Inland Sea. Bull Jpn Soc Sci Fish 51: 529-537 (in Japanese with English Abstract)

Kitada S, Kishino H (2006) Lessons learned from Japanese marine finfish stock enhancement programs. Fish Res 80: $101-112$

Kitada S, Taga Y, Kishino H (1992) Effectiveness of a stock enhancement program evaluated by a two-stage sampling survey of commercial landings. Can J Aquat Fish Sci 49:1573-1582

Kleiber M (1947) Body size and metabolic rate. Physiol Rev 27:511-541

Kleiber M (1961) The fire of life: an introduction to animal energetics. Wiley, New York, NY

> Kobayashi K (2003) The resources recovery plan of the Spanish mackerel in the Seto Inland Sea. Bull Jpn Soc Sci Fish 69:109-114 (in Japanese)

Kono N, Hanamura Y, Nishiyama Y, Fukuda M (1997) Changes in the age composition of Japanese Spanish mackerel, Scomberomorus niphonius, in the western Seto Inland Sea, Japan. Bull Nansei Reg Fish Res Inst 30:1-8 (in Japanese with English Abstract)

Kuwada H, Tsukamoto K (1987) Otolith-tagging of the red sea bream larvae with alizarin complexone-I. Optimum concentration and mark retention. Saibai Giken 16: 93-104 (in Japanese)

> Masuma S, Miyashita S, Yamamoto H, Kumai H (2008) Status of bluefin tuna farming, broodstock management, breeding and fingerling production in Japan. Rev Fish Sci 16:385-390

Ministry of Agriculture, Forestry and Fisheries (1955-2012) Annual statistics of fisheries and aquaculture production in 1953-2010. Association of Agriculture and Forestry Statistics, Tokyo (in Japanese)

> Nagai T (2003) Stock status and stock recovery program of the Spanish mackerel in the Seto Inland Sea. Bull Jpn Soc Sci Fish 69:99-103 (in Japanese)

Nagai T, Takeda Y, Nakamura Y, Shinohara M, Ueta Y, Abe Y, Abe T (1996) Stock status of Spanish mackerel, Scomberomorus niphonius, in the eastern Seto Inland Sea, Japan. Bull Nansei Reg Fish Res Inst 29:19-26 (in Japanese with English Abstract)

National Association for the Promotion of Productive Sea (2007-2010) Annual report for stock recovery plans by the stock enhancement program 2006-2009. National Association for the Promotion of Productive Sea, Tokyo (in Japanese) 
Obata Y, Yamazazki H, Takemori H, Iwamoto A and others (2007) A comparison of survival rates until recruitment for hatchery-released Japanese Spanish mackerel Scomberomorus niphonius with different sizes at release. Bull Jpn Soc Sci Fish 73:55-61 (in Japanese with English Abstract)

Obata Y, Yamazaki H, Iwamoto A, Hamasaki K, Kitada S (2008) Evaluation of stocking effectiveness of Japanese Spanish mackerel in the eastern Seto Inland Sea, Japan. Rev Fish Sci 16:235-243

Peterman RM (1991) Density-dependent marine processes in North Pacific salmonids: lessons for experimental design of large-scale manipulations of fish stocks. ICES Mar Sci Symp 192:69-77

Peters RH (1983) The ecological interactions of body size. Cambridge University Press, Cambridge

Pope JG (1972) An investigation of accuracy of virtual population analysis using cohort analysis. Int Comm Northwest Atl Fish Res Bull 9:65-74

R Development Core Team (2011) R: a language and environment for statistical computing. $\mathrm{R}$ Foundation for Statistical Computing, Vienna. www.r-project.org

Ricker WE (1954) Stock and recruitment. J Fish Res Board Can 11:559-623

Salvanes AGV, Aksnes DL, Giske J (1992) Ecosystem model for evaluating potential cod production in a west Norwegian fjord. Mar Ecol Prog Ser 90:9-22

Shoji J, Tanaka M (2001) Strong piscivory of Japanese Spanish mackerel larvae from their first feeding. J Fish Biol 59:1682-1685

Shoji J, Tanaka M (2005) Daily ration and prey size of juvenile piscivore Japanese Spanish mackerel. J Fish Biol 67: 1107-1118

Shoji J, Tanaka M (2006) Growth-selective survival in piscivorous larvae of Japanese Spanish mackerel Scomberomorus niphonius: early selection and significance of ichthyoplankton prey supply. Mar Ecol Prog Ser 321: 245-254

Shoji J, Kishida T, Tanaka M (1997) Piscivorous habit of Spanish mackerel larvae in the Seto Inland Sea. Fish Sci 63:388-392

Shoji J, Maehara T, Tanaka M (1999a) Diel vertical movement and feeding rhythm of Japanese Spanish mackerel larvae in the central Seto Inland Sea. Fish Sci 65: 726-730

Shoji J, Maehara T, Tanaka M (1999b) Short-term occurrence and rapid growth of Spanish mackerel larvae in the central waters of the Seto Inland Sea, Japan. Fish Sci 65:68-72

Shoji J, Maehara T, Tanaka M (2002) Recruitment of an inherent piscivore, Japanese Spanish mackerel Scomberomorus niphonius (Scombridae). Fish Sci 68(Suppl 1): $59-64$

Shoji J, Maehara T, Tanaka M (2003) Comparative diets and growth of two scombrid larvae, chub mackerel Scomber japonicus and Japanese Spanish mackerel Scomberomorus niphonius, in the central Seto Inland Sea, Japan. UJNR Tech Rep 30:93-103

Shoji J, Maehara T, Tanaka M (2005) Larval growth and mortality of Japanese Spanish mackerel (Scomberomorus niphonius) in the central Seto Inland Sea, Japan. J Mar Biol Assoc UK 85:1255-1261
Sokal RR, Rohlf FJ (1995) Biometry: the principles and practice of statistics in biological research, 3rd edn. W. H. Freeman \& Co, New York, NY

Sugino H, Kashito Y, Oda T (2005) General experiment on seedling production of the Japanese Spanish mackerel Scomberomorus niphonius. Okayama Fish Exp Stn Sci Rep 20:49-53 (in Japanese)

Svåsand T, Kristiansen TS, Pedersen T, Salvanes AGV, Engelsen R, Nævdal G, Nødtvedt M (2000) The enhancement of cod. Fish Fish 1:173-205

Sweeting RM, Beamish RJ, Noakes DJ, Neville CM (2003) Replacement of wild coho salmon by hatchery-reared coho salmon in the Strait of Georgia over the past three decades. N Am J Fish Manag 23:492-502

Takemori H (2006) Growth and maturation of Spanish mackerel Scomberomorus niphonius caught in the eastern Seto Inland Sea. Bull Kagawa Pref Fish Exp Stn 7: 1-11 (in Japanese with English abstract)

Takemori H, Sakamoto H, Ueda Y, Yamazaki H, Iwamoto A (2005a) Mark-recapture experiment using Spanish mackerel, Scomberomorus niphonius, in the eastern Seto Inland Sea. I. Migration. Saibai Giken 32:25-34 (in Japanese with English Abstract)

Takemori H, Sakamoto H, Ueda Y, Yamazaki H, Iwamoto A (2005b) Growth of Spanish mackerel Scomberomorus niphonius in the eastern Seto Inland Sea. Saibai Giken 32:35-41 (in Japanese with English Abstract)

Thomas LM, Holt SA, Arnold CR (1995) Chemical marking techniques for larval and juvenile red drum (Sciaenops ocellatus) otoliths using different fluorescent markers. In: Secor DH, Dean JM, Campana SE (eds) Recent developments in fish otolith research. University of South Carolina Press, Columbia, SC, p 703-717

Tsukamoto K (1988) Otolith tagging of ayu embryo with fluorescent substances. Bull Jpn Soc Sci Fish 54:1289-1295

Tsukamoto K, Kuwada H, Hirokawa J, Oya M, Sekiya S, Fujimoto H, Imaizumi K (1989) Size-dependent mortality of red sea bream, Pagrus major, juveniles released with fluorescent otolith-tags in News Bay, Japan. J Fish Biol 35(Suppl A):59-69

Walters CJ (1988) Mixed stock fisheries and the sustainability of enhancement production for chinook and coho salmon. In: McNeil WJ (ed) Salmon production, management and allocation. Oregon State University Press, Corvallis, OR, p 109-115

Wertheimer AC, Heard WR, Smoker WW (2004) Effects of hatchery releases and environmental variation on wildstock productivity: consequences for sea ranching of pink salmon in Prince William Sound. In: Leber KM, Kitada S, Svåsand T, Blankenship HL (eds) Stock enhancement and sea ranching, 2nd edn. Blackwell Publishing, Oxford, p 307-326

Yamazaki H, Fujimoto H (2003) Reduction of mass mortality of juvenile Spanish mackerel Scomberomorus niphonius by supplementation of vitamin $\mathrm{B}_{1}$ in mass seed production. Saibai Giken 31:19-24 (in Japanese with English Abstract)

> Yamazaki H, Takemori H, Iwamoto A, Okumura S and others (2007) Stocking effectiveness of Japanese Spanish mackerel Scomberomorus niphonius in the eastern Seto Inland Sea. Bull Jpn Soc Sci Fish 73:210-219 (in Japanese with English Abstract)
Editorial responsibility: Ian Fleming,

St. John's, Newfoundland and Labrador, Canada 